\title{
Azithromycin induces apoptosis in airway smooth muscle cells through mitochondrial pathway in a rat asthma model
}

\author{
Liqin $\mathrm{Wu}^{1 \#}$, Juan Yin ${ }^{2 \#}$, Qi Zhang ${ }^{1}$, Meiyan Wang ${ }^{1}$, Wei Dai ${ }^{3}$, Jian Zhou ${ }^{4}$, Yuanrong Dai ${ }^{1}$ \\ ${ }^{1}$ Department of Pulmonary Medicine, the Second Affiliated Hospital of Wenzhou Medical University, Wenzhou, China; ${ }^{2}$ Department of \\ Emergency Medicine, Union Hospital, Tongji Medical College, Huazhong University of Science and Technology, Wuhan, China; ${ }^{3}$ Department \\ of Neurorehabilitation, the Second Affiliated Hospital of Wenzhou Medical University, Wenzhou, China; ${ }^{4}$ Department of Pulmonary Medicine, \\ Zhongshan Hospital, Fudan University, Shanghai, China \\ Contributions: (I) Conception and design: L Wu, J Yin; (II) Administrative support: J Zhou, Y Dai; (III) Provision of study materials or patients: Y Dai; \\ (IV) Collection and assembly of data: L Wu, J Yin, Q Zhang; (V) Data analysis and interpretation: L Wu, J Yin, M Wang; (VI) Manuscript writing: \\ All authors; (VII) Final approval of manuscript: All authors. \\ "These authors contributed equally to this work. \\ Correspondence to: Yuanrong Dai. Department of Pulmonary Medicine, the Second Affiliated Hospital of Wenzhou Medical University, 109 Xueyuan \\ Road, Wenzhou 325027, China. Email: daiyr@126.com; Jian Zhou. Department of Pulmonary Medicine, Zhongshan Hospital, Fudan University, \\ 180 Fenglin Road, Shanghai 200032, China. Email: zhou.jian@fudan.edu.cn.
}

Background: The proliferation of airway smooth muscle cells (ASMCs) is a key feature of airway remodeling in asthma. Azithromycin (AZM) has been shown to decrease bronchial hyperresponsiveness and airway inflammation in asthmatics; however, the role of AZM in ASMC proliferation remains unclear. Thus, we investigated the effect of AZM on ASMC proliferation in a rat model of experimental asthma.

Methods: We isolated ASMCs from rats sensitized and challenged by ovabulmin (OVA), and then treated with different concentrations of AZM. Cytotoxicity of ASMC was evaluated by Cell Counting Kit-8 (CCK8) assay, morphological change was examined with laser confocal microscope after Annexin V/propidium iodide (PI) double staining, mitochondrial membrane potential was determined with JC-1 staining, and the expression of cytochrome $\mathrm{C}$ was examined by western blot.

Results: The relative surface areas of airway wall and smooth muscle layers in OVA-sensitized rats were significantly increased compared to those in the control group. Furthermore, in OVA-sensitized rats, the mitochondrial membrane potential of ASMC was higher, while the expression of mitochondria cytochrome $\mathrm{C}$ was lower compared to that in control rats. After AZM treatment, ASMC apoptosis was increased, mitochondrial membrane potential reduced, and the protein level of cytosolic cytochrome $\mathrm{C}$ was increased.

Conclusions: This study demonstrated that AZM increased the apoptosis of ASMCs through a mitochondrial pathway, which might play an important role in ASMs proliferation during asthmatic remodeling.

Keywords: Azithromycin (AZM); asthma; airway smooth muscle cells (ASMCs); apoptosis; mitochondria

Submitted Jun 08, 2021. Accepted for publication Jul 15, 2021.

doi: $10.21037 / \mathrm{atm}-21-3478$

View this article at: https://dx.doi.org/10.21037/atm-21-3478

\section{Introduction}

Asthma is a heterogeneous disease which is influenced by both genetic and environmental factors (1). It is characterized as eosinophilic inflammation of the airways and structural changes of bronchial tissues, known as airway remodeling (2). Hours are needed to complete the process of cytokine-induced recruitment of eosinophils from the blood to the airways after acute allergen challenge (3). Airway remodeling refers to a number of processes 
including increased epithelial cell disruption and airway smooth muscle mass, and subepithelial fibrosis. Thus, the reduction of airway smooth muscle cell (ASMC) apoptosis might participate in the remodeling process of asthma (4-6).

Our previous study found that macrolides could reduce airway inflammation by inhibiting the PI3K- $\delta$ /Akt signaling pathway and upregulating histone deacetylase 2 (HDAC2) expression (7). Several clinical studies have shown that azithromycin (AZM), an antibiotic, has the ability to reduce bronchial hyperresponsiveness and neutrophilic airway inflammation (8). Furthermore, it has been demonstrated that AZM has an antiproliferative and autophagic effect on ASMCs in adult rabbits (9), and that AZM ameliorates airway remodeling via inhibiting airway epithelium apoptosis (10). However, the underlying mechanism of AZM-induced ASMC apoptosis is still not clear.

There are many mechanisms that cause apoptosis, and whether mitochondrial pathway is involved in them is the focus of research. The most important detection indexes of mitochondrial pathway are mitochondrial membrane potential and cytochrome C. Mitochondria play an important role in the apoptotic pathway of respiratory epithelial cells in asthma (11). As an intermembranous mitochondrial protein, cytochrome $\mathrm{C}$ triggers the caspase activation cascade by binding to a cytoplasmic scaffolding protein, and then initiates apoptosis in response to cellular stress (12). At present, there are no reports on the prevention and treatment of asthma by AZM through mitochondrial pathway mediated apoptosis. To explore the mechanism of macrolide antibiotics on ASMCS in asthmatic rats can provide new strategies and new ideas for the prevention and treatment of asthma. Furthermore, patients who have high treatment compliance will benefit from effective intervention. Considering mitochondrial activity is essential in cell apoptosis, we hypothesized that AZM might induce ASMC apoptosis through the mitochondrial pathway.

We present the following article in accordance with the ARRIVE reporting checklist (available at https://dx.doi. org/10.21037/atm-21-3478).

\section{Methods}

\section{Animal model}

Male Sprague Dawley rats [specific pathogen-free (SPF) grade, 6 weeks old] were used in this study. We randomly allocated 20 Sprague Dawley rats to two groups, with 10 in the control group and 10 in the asthma group. The animals had no access to solid food but received free access to water $12 \mathrm{~h}$ before the experiments. The experimental protocol (No. wydw2016-0124) was approved by the Committee of Animal Care at Wenzhou Medical University. All animals were handled in accordance with the Guideline for the Care and Use of Laboratory Animals. A protocol was prepared before the study without registration. Rats were sensitized on days 1 and 8 by intraperitoneal (ip) injection of $10 \mathrm{mg}$ of ovabulmin (OVA) (Sigma, St. Louis, MO, USA) mixed with $10 \%$ aluminum hydroxide $\mathrm{Al}(\mathrm{OH})_{3}$ suspended in a total volume of $1 \mathrm{~mL}$ (13). Then, from day 15, animals were challenged with $1 \%$ OVA aerosol for 30 min every other day for 8 weeks (14). Saline injection (ip) and nebulization were used for the control rats. The rats were anesthetized and humanely killed $24 \mathrm{~h}$ after the last challenge.

\section{Histological examination}

After the rats were sacrificed, the descending aorta was cut, and their lungs were carefully removed from the thoracic cavity. The right middle lobes of the lungs were fixed in $4 \%$ paraformaldehyde, and then imbedded in paraffin. After deparaffinization and staining with hematoxylin and eosin (HE), the sections (5 $\mu \mathrm{m}$ thick) were morphometrically analyzed to determine airway wall and smooth muscle content. Basement membrane perimeter $(\mathrm{Pbm})$, bronchial total area $(\mathrm{At})$, lumen area (Ac), the outer edge of the tracheal smooth muscle area $(\mathrm{AMe})$, and the inner edge of the tracheal smooth muscle area (AMi) were quantified by commercially available imaging software (Image pro plus 6.0; Media Cybernetics Inc., Rockville, MD, USA). In addition, bronchial wall thickness (Wat) and smooth muscle thickness (Wam) were calculated using two formulas, as follows: Wat $=(\mathrm{At}-\mathrm{Ac}) / \mathrm{Pbm} ; \mathrm{Wam}=(\mathrm{AMe}-\mathrm{AMi}) / \mathrm{Pbm}(15)$. For each index, three bronchioles from each section were chosen and measured to determine the mean value.

\section{Cell culture}

According to the method described by Dai et al. (16), rat airway smooth muscle was separated, and then minced into $1 \mathrm{~mm}^{3}$ fragments. The tissues were incubated in $\mathrm{Ca}^{2+}$ free physiological salt solution containing $2 \mathrm{~g} / \mathrm{L}$ collagenase, $5 \mathrm{~g} / \mathrm{L}$ papain, and $2 \mathrm{~g} / \mathrm{L}$ bovine serum albumin (BSA) for $30 \mathrm{~min}$ at $37^{\circ} \mathrm{C}$. Then, the isolated ASMCs were cultured in Dulbecco's modified Eagle's medium (DMEM), containing 
$20 \%$ fetal bovine serum (FBS). Specific mouse monoclonal antibodies $\alpha$-actin (Santa Cruz Biotechnology, Inc., Dallas, TX, USA) was used to verify the purity and identification of ASMCs, which were used between passages 3 and 7 . At $24 \mathrm{~h}$ before drug treatment, ASMCs were transferred to serumfree DMEM for synchronization when reaching nearly $70 \%$ confluence, and then cultured with AZM $(0.1,1,10$, and $100 \mu \mathrm{g} / \mathrm{mL}$ ). After $24 \mathrm{~h}$, the cells were collected for further analysis.

\section{Cytotoxicity assay}

Cell cytotoxicity assay was determined by Cell Counting Kit-8 (CCK-8) assay. A total of $100 \mu \mathrm{L}$ of cell suspension $\left(5,000\right.$ cells/well) was pre-incubated for $24 \mathrm{~h}$ (at $37^{\circ} \mathrm{C}, 5 \%$ $\mathrm{CO}_{2}$ ). After adding $10 \mu \mathrm{L}$ of various concentrations of $\mathrm{AZM}$ for $24 \mathrm{~h}$, we incubated each well of the plates with $10 \mu \mathrm{L}$ of CCK-8 solution for 1-4 h. The absorbance was measured at $450 \mathrm{~nm}$ by a microplate reader (Bio-Tek, Winooski, VT, USA).

\section{The Annexin V-FITC/propidium iodide (PI) assay}

After cells were treated with AZM for $24 \mathrm{~h}, 5 \mu \mathrm{L}$ Annexin $\mathrm{V}$-FITC and $5 \mu \mathrm{L}$ PI were added to the culture medium, and then the cells were transferred onto coverslips (KeyGen Biotech., Nanjing, China). Samples were kept in the dark at room temperature for $10 \mathrm{~min}$, and then examined under a laser confocal microscope (Olympus, Tokyo, Japan).

\section{Mitochondrial membrane potential assay}

JC-1 dye (KeyGen Biotech.) was used to measure mitochondrial membrane potential. ASMCs $\left(1 \times 10^{6}\right.$ cells/ well) were treated with AZM for $24 \mathrm{~h}$. After washing, ASMCs were incubated with pre-warmed JC-1 solution for $15 \mathrm{~min}$ at $37^{\circ} \mathrm{C}$, and then examined with flow cytometry (Facsaria, Becton, Dickinson and Co. Biosciences, Franklin Lakes, NJ, USA). Data was analyzed using CellQuest software (BD Biosciences, USA).

\section{Western blot analysis}

Cultured ASMCs were frozen and lysed in lysis buffer. Total proteins were separated by $8 \%$ sodium dodecyl sulfate-polyacrylamide gel electrophoresis (SDS-PAGE) and transferred onto a nitrocellulose membrane. Block membrane [in $30 \mathrm{~mL}$ phosphate buffered saline (PBS) +
$5 \%$ non-fat dry milk $+0.1 \%$ Tween 20 in a small dish on a shaker] was then incubated with cytochrome $\mathrm{C}$ antibody (1:1,000; Cell Signaling Technology, USA). Glyceraldehyde 3-phosphate dehydrogenase (GAPDH) antibody (1:1,000; Cell Signaling Technology, USA) was used for control.

\section{Statistical analysis}

The data were presented as mean \pm standard deviation (SD). Student's $t$-test for unpaired samples was used for comparison of means between asthmatic and control groups. One-way analysis of variance (ANOVA) was used for multiple comparisons among more than two groups. A $\mathrm{P}$ value $<0.05$ was considered statistically significant.

\section{Results}

\section{Effects of AZM on the proliferation of ASMCs}

The HE staining of lung tissue showed that there was a large number of inflammatory cell infiltration, the majority of which were eosinophilic cells. There was also evidence of airway epithelial damage and smooth muscle layer thickening in OVA-sensitized rats compared to the lungs of control rats (Figure 1A). The relative area of Wat and Wam in OVA-sensitized rats was significantly increased compared to those in control rats (Table 1, Figure 1B). To evaluate the effects of AZM on ASMC proliferation, different concentrations $(0.1,1,10$, and $100 \mu \mathrm{g} / \mathrm{mL})$ of $A Z M$ were applied in culture medium for 24 h. As shown in Figure 2, treatment with AZM reduced the viability of ASMCs to the levels of $72.71 \% \pm 13.16 \%$ at $0.1 \mu \mathrm{g} / \mathrm{mL}, 66.42 \% \pm 4.90 \%$ at $1 \mu \mathrm{g} / \mathrm{mL}, 64.92 \% \pm 2.28 \%$ at $10 \mu \mathrm{g} / \mathrm{mL}$, and $51.45 \% \pm 2.83 \%$ at $100 \mu \mathrm{g} / \mathrm{mL}$, indicating that AZM has dose-response effects on inhibiting ASMC proliferation.

In order to confirm the antiproliferative effect of $\mathrm{AZM}$, the morphologic features of cell apoptosis were examined under a laser confocal microscope after Annexin $\mathrm{V}$ and PI double staining. As shown in Figure $3 A, B$, there was no FITC-Annexin V/PI positively stained cells in the control and OVA-sensitized groups. In contrast, Figure 3C,D,E shows that the cytoplasm of ASMCs was gradually stained green with Annexin V-FITC after treatment with $0.1,1$, and $10 \mu \mathrm{g} / \mathrm{mL}$ of AZM. Of note, Figure $3 F$ showed that the nucleus of ASMCs appeared red with PI staining after treatment with $100 \mu \mathrm{g} / \mathrm{mL}$ AZM. These results demonstrated that AZM induced early and late phase of ASMC apoptosis in a dose-dependent manner. 

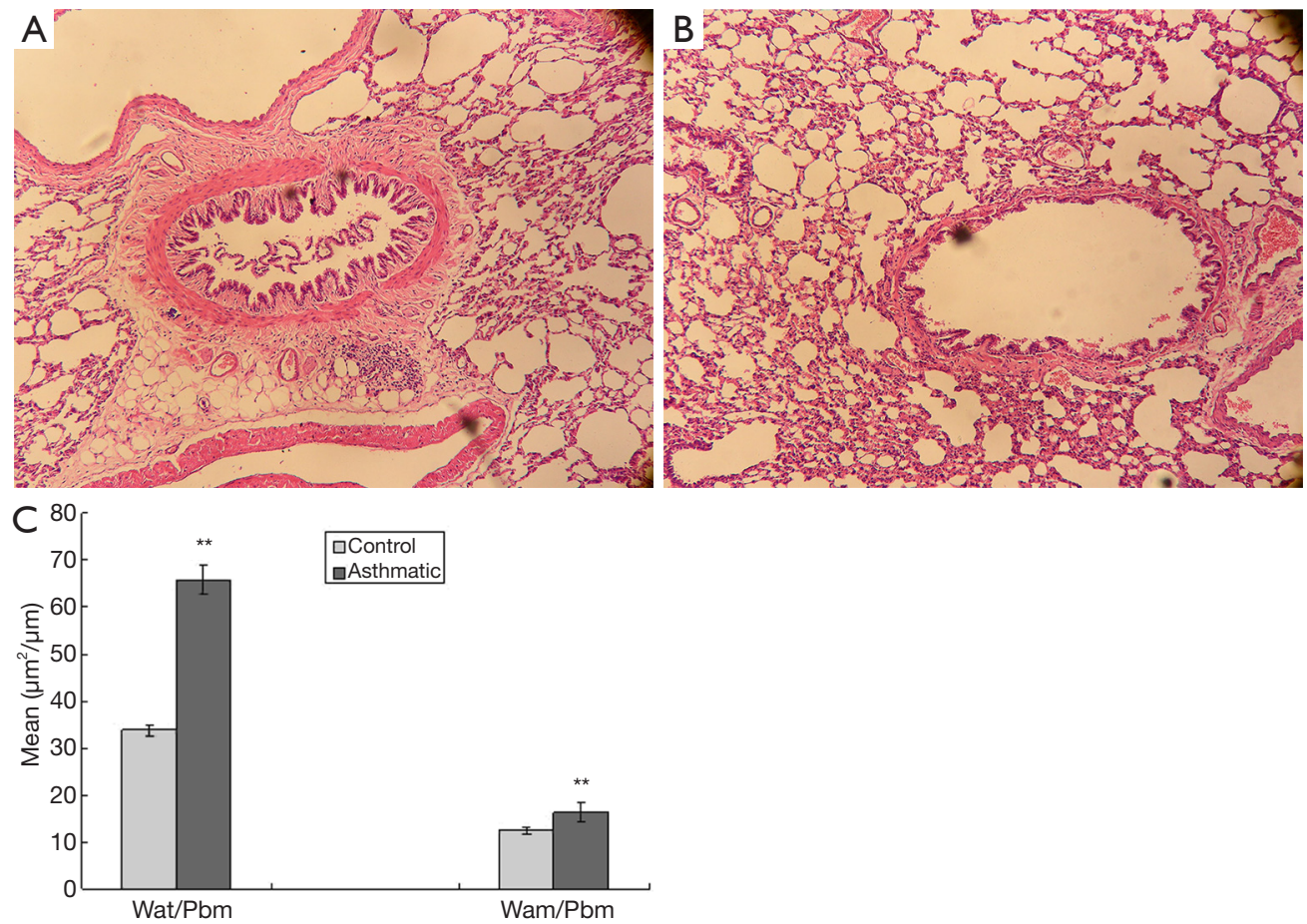

Figure 1 Histologic changes in bronchiole. (A) HE staining of lung tissue from control (a) and OVA-challenged OVA-sensitized (b) rats. Original magnification $\times 100$. (B) The relative area of Wat $/ \mathrm{Pbm}$ and $\mathrm{Wam} / \mathrm{Pbm}$ in OVA-sensitized rats was significantly increased compared to those in control. Data are presented as mean $\pm \mathrm{SD}(\mathrm{n}=8)$. **, $\mathrm{P}<0.01$ vs. control group. HE, hematoxylin and eosin; OVA, ovabulmin; Wat, the total bronchial wall area; Pbm, basement membrane perimeter Wam, smooth muscle thickness; SD, standard deviation.

Table 1 Difference of Pbm, Wat, Wam in four groups $(\bar{x} \pm s, \mathrm{n}=6)$

\begin{tabular}{lcccc}
\hline Group & Number & $\mathrm{Pbm}(\mu \mathrm{m})$ & Wat $/ \mathrm{Pbm}\left(\mu \mathrm{m}^{2} / \mu \mathrm{m}\right)$ & Wam/Pbm $\left(\mu \mathrm{m}^{2} / \mu \mathrm{m}\right)$ \\
\hline Control & 6 & $2160 \pm 338.71$ & $31.94 \pm 5.12$ & $11.30 \pm 1.70$ \\
Asthmatic & 6 & $2101 \pm 838.95$ & $53.73 \pm 20.27^{\star}$ & $16.75 \pm 5.34^{\star}$ \\
F & & 0.026 & 6.515 & 5.668 \\
P & $>0.05$ & $<0.05$ & $<0.05$ \\
\hline
\end{tabular}

*, $\mathrm{P}<0.05$ vs. control group. Pbm, basement membrane perimeter; Wat, the total bronchial wall area; Wam, smooth muscle thickness.

\section{Effects of AZM on mitochondrial membrane potential in ASMCs}

To determine whether AZM affects mitochondrial $\Delta \varphi \mathrm{m}$ in ASMCs, we performed flow cytometry with JC-1 fluorescent staining to identify two cell populations with different $\Delta \varphi \mathrm{m}$, namely, one population with high $\Delta \varphi \mathrm{m}$ (gated region $\mathrm{P} 2$, stained in green), and the other with low $\Delta \varphi \mathrm{m}$ (gated region P3, stained in blue). As shown in Figure 4A, flow cytometry analysis revealed that $72.4 \%$ cells stained in green and $27.3 \%$ cells stained in blue were detected in control rat
ASMCs. In contrast, a significantly increased percentage of green cells and decreased percentage of blue cells was seen in OVA-sensitized rat ASMCs. As shown in Table 2, Figure $4 B, C$, the low mitochondrial membrane potential of asthmatic group was significantly reduced $(\mathrm{P}<0.01)$ and the high mitochondrial membrane potential was significantly increased $(\mathrm{P}<0.01)$ relative to control group; Compared with asthmatic group and control group, the low mitochondrial membrane potential at each concentration of AZM intervention group was significantly increased $(\mathrm{P}<0.01)$ and the high mitochondrial membrane potential was significantly 


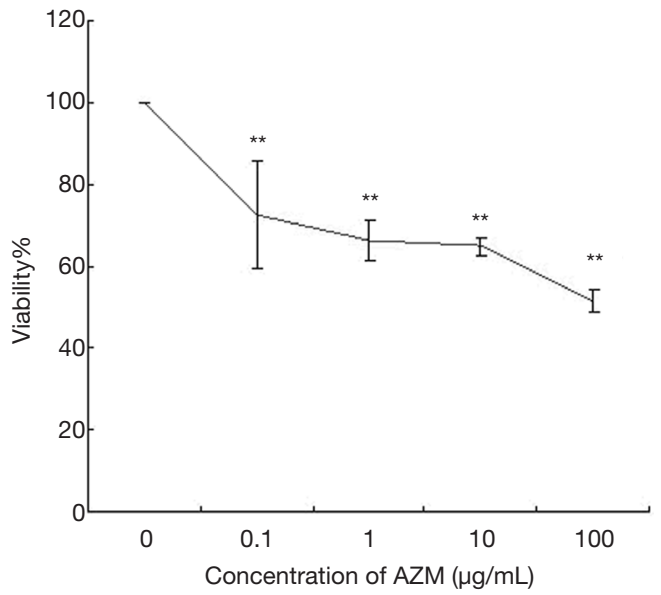

Figure 2 Cytotoxicity of AZM on ASMC. ASMCs were incubated with saline or AZM with various concentrations $(0.1,1,10$, and $100 \mu \mathrm{g} / \mathrm{mL})$. Data are presented as mean $\pm \mathrm{SD}(\mathrm{n}=3) .{ }^{* *}, \mathrm{P}<0.01$ vs. saline. AZM, azithromycin; ASMC, airway smooth muscle cell; $\mathrm{SD}$, standard deviation.
Table 2 Effects of AZM on mitochondrial membrane potential in ASMCs

\begin{tabular}{lcc}
\hline Group & $\begin{array}{c}\text { High mitochondrial } \\
\text { membrane potential (\%) }\end{array}$ & $\begin{array}{c}\text { Low mitochondrial } \\
\text { membrane potential }(\%)\end{array}$ \\
\hline Control & $62.30 \pm 7.12$ & $37.45 \pm 7.18$ \\
Asthmatic & $74.95 \pm 6.56^{\star \star}$ & $24.62 \pm 7.05^{\star *}$ \\
$0.1 \mu \mathrm{g} / \mathrm{mL}$ & $48.23 \pm 2.57^{\star \star \# \#}$ & $51.45 \pm 2.59^{\star \star \# \#}$ \\
$1 \mu \mathrm{g} / \mathrm{mL}$ & $37.43 \pm 2.55^{\star \star \# \#}$ & $62.28 \pm 2.61^{\star * \# \#}$ \\
$10 \mu \mathrm{g} / \mathrm{mL}$ & $55.67 \pm 5.62^{\star \star \# \#}$ & $44.05 \pm 5.62^{\star * \# \#}$ \\
$100 \mu \mathrm{g} / \mathrm{mL}$ & $31.83 \pm 1.95^{\star \star \# \#}$ & $67.83 \pm 1.85^{\star \star \# \#}$ \\
\hline **, $\mathrm{P}<0.01$ vs. control group; \#\#, P<0.01 vs. asthmatic group \\
incubated without AZM treatment. AZM, azithromycin; ASMC, \\
airway smooth muscle cell.
\end{tabular}

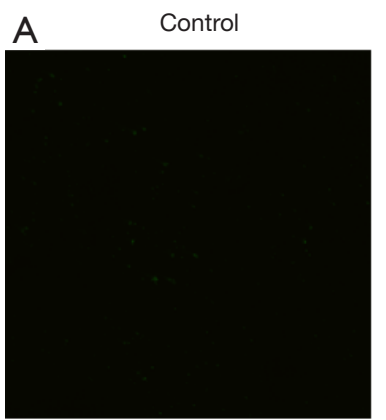

D $\quad 1 \mu \mathrm{g} / \mathrm{mL}$

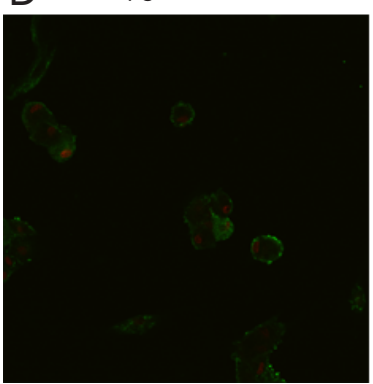

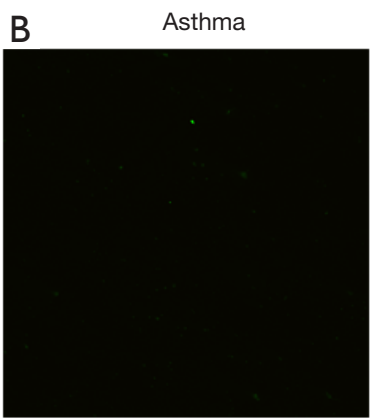

E

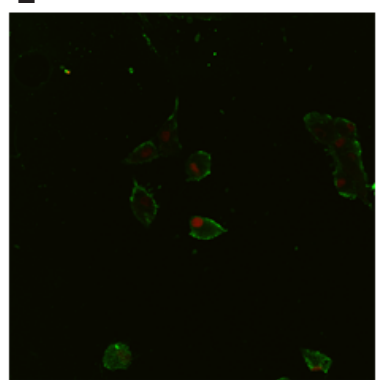

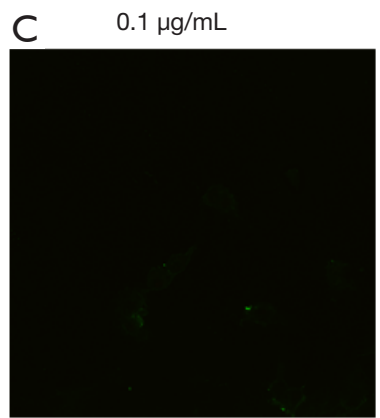

F $\quad 100 \mu \mathrm{g} / \mathrm{mL}$

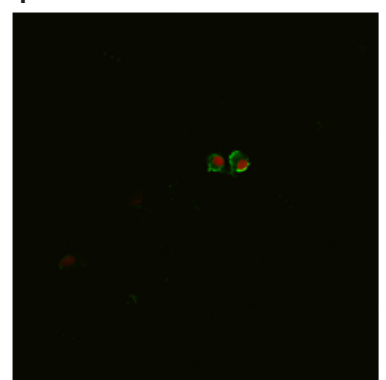

Figure 3 Effects of AZM on ASMCs apoptosis. Annexin V and PI double staining of ASMCs were examined with a laser confocal microscope from control (A) and asthmatic (B) rats incubated without AZM, and from OVA-sensitized rats incubated with AZM under different concentrations $(0.1,1,10$, and $100 \mu \mathrm{g} / \mathrm{mL})(\mathrm{C}, \mathrm{D}, \mathrm{E}, \mathrm{F})$. Images are shown at 200× magnification. Green fluorescence indicated Annexin V-FITC staining positive. Red indicated PI staining positive. AZM, azithromycin; ASMC, airway smooth muscle cell; PI, propidium iodide; OVA, ovabulmin. 

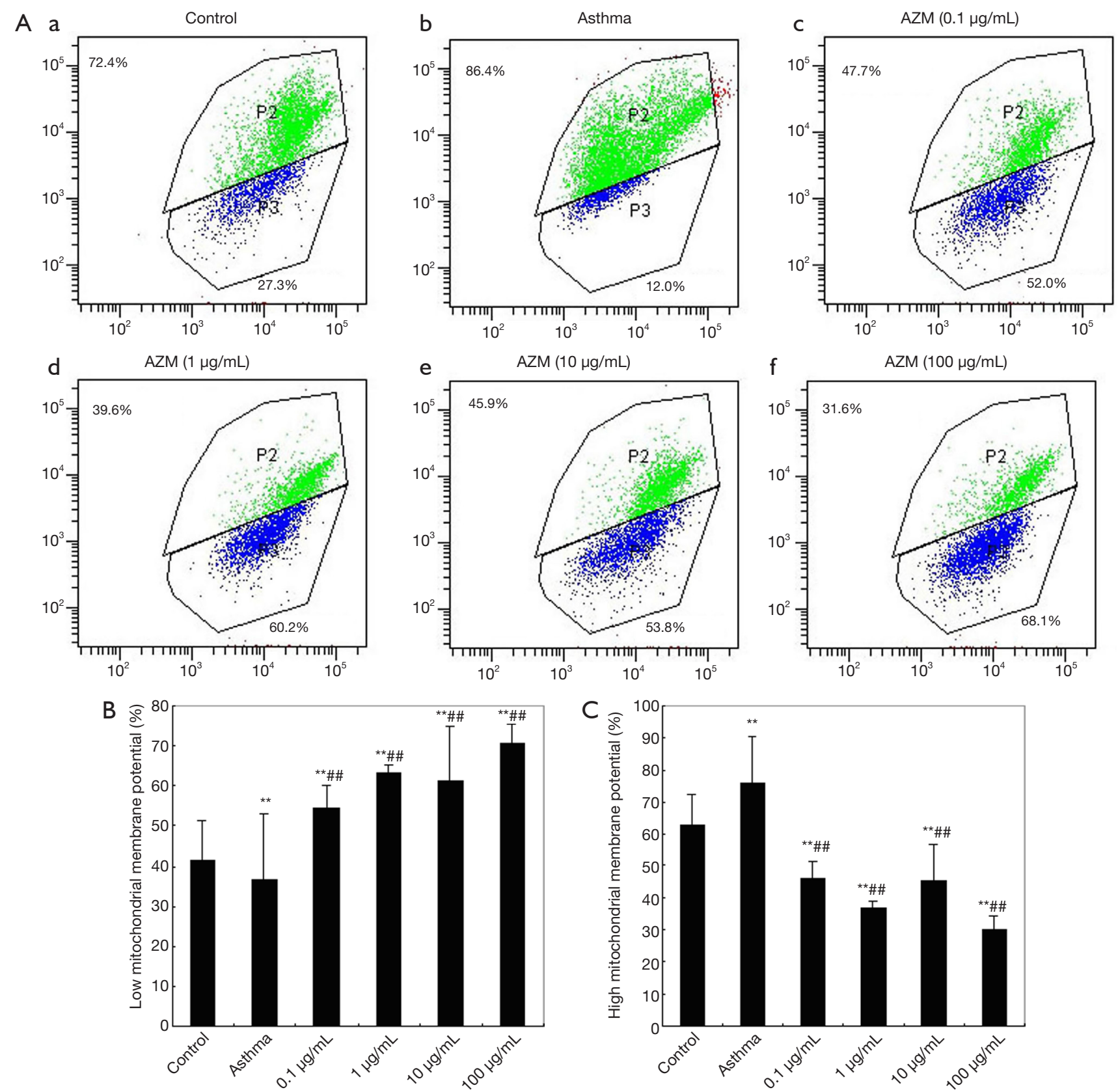

Figure 4 Effects of AZM on mitochondrial membrane potential in rat ASMCs. (A) ASMCs from control (a) and OVA-sensitized rats incubated without AZM, and from asthmatic (b) rats incubated with AZM under different concentrations $(0.1,1,10$, and $100 \mu \mathrm{g} / \mathrm{mL})$ (c,d,e,f) for $24 \mathrm{~h}$, stained with fluorescent dye JC-1 for $30 \mathrm{~min}$, and subjected to flow cytometry analysis (ex =488 nm, em =530 nm). (B) The percentage of cells with high $\Delta \varphi \mathrm{m}$ was represented as histograms. (C) The percentage of cells with low $\Delta \varphi \mathrm{m}$ was represented as histograms. Data are presented as mean $\pm \mathrm{SD}$. Three independent experiments were performed for each condition. ${ }^{* *}, \mathrm{P}<0.01$ vs. control group; ${ }^{\# \#}$, $\mathrm{P}<0.01$ vs. asthmatic group incubated without AZM treatment. AZM, azithromycin; ASMC, airway smooth muscle cell; SD, standard deviation. 
reduced $(\mathrm{P}<0.01)$. As a result, $\mathrm{AZM}$ significantly decreased the $\triangle \varphi \mathrm{m}$ of OVA-sensitized rat ASMCs in a dose-dependent manner. Thus, we concluded that AZM induced apoptosis through alternating the mitochondrial membrane potential of OVA-sensitized rat ASMCs.

\section{Expression of cytochrome C in ASMCs}

In order to confirm that AZM induced apoptosis of ASMCs

Table 3 Western blot

\begin{tabular}{lcc}
\hline Group & $\begin{array}{c}\text { Cytosolic } \\
\text { cytochrome C (OD) }\end{array}$ & $\begin{array}{c}\text { Mitochondrial } \\
\text { cytochrome C (OD) }\end{array}$ \\
\hline Control & $1.028 \pm 0.043$ & $0.087 \pm 0.006$ \\
Asthmatic & $0.825 \pm 0.029^{\star}$ & $0.068 \pm 0.005^{\star \star}$ \\
$0.1 \mu \mathrm{g} / \mathrm{mL}$ & $1.622 \pm 0.205^{\star \# \#}$ & \\
$1 \mu \mathrm{g} / \mathrm{mL}$ & $2.174 \pm 0.344^{\star \star \# \#}$ & \\
$10 \mu \mathrm{g} / \mathrm{mL}$ & $3.175 \pm 0.264^{\star \star \# \#}$ & \\
$100 \mu \mathrm{g} / \mathrm{mL}$ & $3.445 \pm 0.267^{\star \star \# \#}$ & \\
\hline
\end{tabular}

*, $\mathrm{P}<0.05$, **, $\mathrm{P}<0.01$ vs. control group; ${ }^{\# \#, ~} \mathrm{P}<0.01$ vs. asthmatic group incubated without AZM treatment. AZM, azithromycin; OD, optical density. through a mitochondrial pathway, we next examined the expression level of cytochrome C in ASMCs. As shown in Table 3, Figure $5 A, B$, cytosolic cytochrome C from OVAsensitized rats was significantly reduced compared to that from control group rats. Upon administration of AZM, cytosolic cytochrome $\mathrm{C}$ was markedly increased, while there was no mitochondrial cytochrome $\mathrm{C}$ detected. The results indicated that $\mathrm{AZM}$ induced the releasing of cytochrome $\mathrm{C}$ protein from mitochondria.

\section{Discussion}

ASMCs reversible switching between contractile and proliferative phenotypes, is considered to contribute to proliferative diseases. Airway remodeling is one of the main features of asthma and involves structural changes of airway smooth muscle, epithelia, extracellular matrix, and blood vessels $(17,18)$. Airway smooth muscle remodeling has important effects on airway responsiveness and severity of asthma (18). In the present study, we found that the thickness and relative area of the airway wall and smooth muscle layer were all increased in OVA-sensitized rats, which confirmed that we had successfully established an asthmatic rat model. The drug AZM decreases apoptosis

Cytochrome c

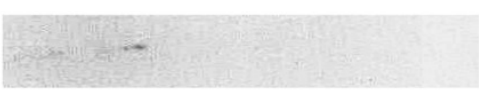

GAPDH (Mitochondtia)

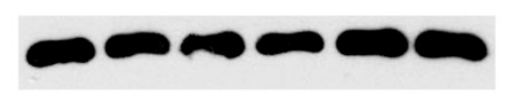

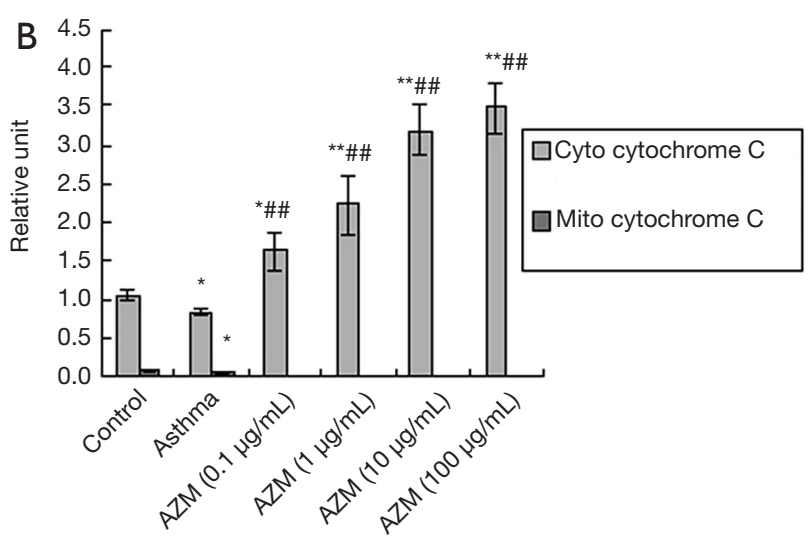

Figure 5 The effects of AZM on the expression of cytochrome C. (A) The expression of cytochrome C was analyzed by western blot. (B) Cytosolic cytochrome $\mathrm{C}$ from OVA-sensitized rats was significantly reduced compared to that from control group rats. Data are presented as mean $\pm \mathrm{SD}$ from at least three independent experiments. ${ }^{*}, \mathrm{P}<0.05,{ }^{* *}, \mathrm{P}<0.01$ vs. control group; ${ }^{\# \#}, \mathrm{P}<0.05$ vs. asthmatic group incubated without AZM treatment. AZM, azithromycin; OVA, ovabulmin; SD, standard deviation. 
through mitochondrial pathways in OVA-sensitized rat ASMCs, and thus might play an important role in airway smooth muscle remodeling in asthmatic rats.

In our study, AZM was administrated at a concentration that equaled the lung tissue concentration of $8.93 \mathrm{mg} / \mathrm{L}$ (19), which did not upregulate the caspase- 3 expression and did not change the percentage of dead cells after AZM treatment for $24 \mathrm{~h}$, indicating that AZM did not induce apoptosis in control rat ASMCs (9). In this study, we investigated the morphologic features of cell apoptosis with Annexin V and PI double staining under laser confocal microscope and revealed the early and late phase of apoptosis of ASMCs upon administration of AZM with dose-response effects in ASMCs isolated from OVAsensitized rats. The results indicated that AZM might only induce apoptosis of ASMCs isolated from OVAsensitized rats. Patients with persistent symptomatic asthma experience fewer asthma exacerbations and improved quality of life when treated with AZM (20). Studies have reported that AZM could reduce bronchial hyper responsiveness and airway inflammation in asthmatic patients $(8,21)$.

Recently, it has been shown that AZM inhibits the expression of multiple signaling molecules, such as tumor necrosis factor- $\alpha$ (TNF- $\alpha$ ), interleukin-8 (IL-8), IL-6, nuclear factor kappa-B (NF-kB), ERK1/2, and JNK in epithelial cells from a cystic fibrosis model, which suggests that AZM has an immunomodulatory effect (22). Combined treatment of bortezomib and clarithromycin (CAM) or AZM enhances cytotoxicity in several myeloma cell lines, induces the proapoptotic transcription factor C/EBP homologous protein (CHOP), and subsequently upregulates the expression levels of proapoptotic genes including $B I M$, $B A X, D R 5$, and TRB3 (23). It has been shown that $\mathrm{BH} 3$ domain-only molecules regulate the caspase activation cascade, initiating apoptotic response $(24,25)$.

In ASMCs of asthma, the signal transduction pathway of $\mathrm{PKC} \alpha$ may be involved in cell proliferation, which is induced by the opening of mitoK $\mathrm{K}_{\mathrm{ATP}}$ and the depolarization of $\Delta \varphi \mathrm{m}$ (26). Mitochondrial membrane potential is a sensitive parameter reflecting minor changes of the cellular environment and plays an important role in cell apoptosis (27). Mitochondrial membrane potential is formed when proton transfers from the mitochondrial matrix to the intermembranous space. When membrane potential falls, permeability transition pores will open, which allows the release of small molecules, including apoptosis initiating factors such as cytochrome $\mathrm{C}$, from the mitochondria through the pores. The released cytochrome $\mathrm{C}$ binds to apoptotic protease activating factor-1, initiates the caspase activation cascade, and induces cellular apoptosis (27). Based on the cytotoxicity assay and Annexin V and PI double staining experiments, our in vitro experiments showed that a lower membrane potential and higher viability of ASMCs were detected in OVA-sensitized rats, which provided further evidence that mitochondrial membrane potential is altered during asthmatic airway remodeling.

Furthermore, our study showed that the level of cytochrome $\mathrm{C}$ in cytoplasm from control group rats was significantly higher than that in the asthmatic rat group. In ASMCs from OVA-sensitized rats, the level of cytochrome C was lower compared to ASMCs from the control group, while AZM increased the protein expression of cytochrome C. These results demonstrated that AZM could increase apoptosis in asthmatic airways through a mitochondrial dependent pathway.

\section{Conclusions}

In summary, this study demonstrated that decreased ASMC apoptosis, higher mitochondrial membrane potential, and lower expression levels of mitochondrial cytochrome $\mathrm{C}$ may play an important role in ASMC remodeling of asthmatic rats. It was shown that AZM can upregulate cytochrome C protein level, leading to cell apoptosis in asthmatic rat ASMCs. Therefore, our study provides a new insight into the mechanisms of AZM-induced ASMC apoptosis in asthma airways with a potential new target for future asthma treatment.

\section{Acknowledgments}

Funding: This project was supported by a grant from the Natural Science Foundation of Zhejiang Province (Y2080466).

\section{Footnote}

Reporting Checklist: The authors have completed the ARRIVE reporting checklist. Available at https://dx.doi. org/10.21037/atm-21-3478

Data Sharing Statement: Available at https://dx.doi. org/10.21037/atm-21-3478

Conflicts of Interest: All authors have completed the ICMJE uniform disclosure form (available at https://dx.doi. 
org/10.21037/atm-21-3478). The authors have no conflicts of interest to declare.

Ethical Statement: The authors are accountable for all aspects of the work in ensuring that questions related to the accuracy or integrity of any part of the work are appropriately investigated and resolved. The experimental protocol (No. wydw2016-0124) was approved by the Committee of Animal Care at Wenzhou Medical University. All animals were handled in accordance with the Guideline for the Care and Use of Laboratory Animals.

Open Access Statement: This is an Open Access article distributed in accordance with the Creative Commons Attribution-NonCommercial-NoDerivs 4.0 International License (CC BY-NC-ND 4.0), which permits the noncommercial replication and distribution of the article with the strict proviso that no changes or edits are made and the original work is properly cited (including links to both the formal publication through the relevant DOI and the license). See: https://creativecommons.org/licenses/by-nc-nd/4.0/.

\section{References}

1. Dai Y, Qiu H, Sun S, et al. Age-dependent effect of ambient ozone on emergency asthma hospitalizations in Hong Kong. J Allergy Clin Immunol 2018;141:15321534.e5.

2. Li HT, Ye C, Zhou M, et al. Moxifloxacin suppresses airway inflammation and modulates expression of caveolin-1 and flotillin-1 in airway smooth muscle cells of asthmatic rats. Ann Transl Med 2019;7:469.

3. Hsiue TR, Lei HY, Hsieh AL, et al. Time course of pharmacological modulation of peak eosinophilic airway inflammation after mite challenge in guinea pigs: a therapeutic approach. Int Arch Allergy Immunol 1999;119:297-303.

4. Samitas K, Carter A, Kariyawasam HH, et al. Upper and lower airway remodelling mechanisms in asthma, allergic rhinitis and chronic rhinosinusitis: The one airway concept revisited. Allergy 2018;73:993-1002.

5. Ding MJ, Wang LX, Dai YR. Changes of airway smooth muscle cell apoptosis in asthmatic airway remodeling and the effect of dexamethasone in rats. Zhonghua Jie $\mathrm{He} \mathrm{He}$ Hu Xi Za Zhi 2008;31:607-10.

6. Yap HM, Israf DA, Harith HH, et al. Crosstalk between signaling pathways involved in the regulation of airway smooth muscle cell hyperplasia. Front Pharmacol
2019;10:1148.

7. Xia $M, X u H$, Dai $W$, et al. The role of HDAC2 in cigarette smoke-induced airway inflammation in a murine model of asthma and the effect of intervention with roxithromycin. J Asthma 2018;55:337-44.

8. Piacentini GL, Peroni DG, Bodini A, et al. Azithromycin reduces bronchial hyperresponsiveness and neutrophilic airway inflammation in asthmatic children: a preliminary report. Allergy Asthma Proc 2007;28:194-8.

9. Stamatiou R, Paraskeva E, Boukas K, et al. Azithromycin has an antiproliferative and autophagic effect on airway smooth muscle cells. Eur Respir J 2009;34:721-30.

10. Liu Y, Pu Y, Li D, et al. Azithromycin ameliorates airway remodeling via inhibiting airway epithelium apoptosis. Life Sci 2017;170:1-8.

11. Prakash YS, Pabelick CM, Sieck GC. Mitochondrial dysfunction in airway disease. Chest 2017;152:618-26.

12. Kallergi E, Kalef-Ezra E, Karagouni-Dalakoura K, et al. Common players in mitochondria biogenesis and neuronal protection against stress-induced apoptosis. Neurochem Res 2014;39:546-55.

13. Palmans E, Kips JC, Pauwels RA. Prolonged allergen exposure induces structural airway changes in sensitized rats. Am J Respir Crit Care Med 2000;161:627-35.

14. Dejager L, Dendoncker K, Eggermont M, et al. Neutralizing TNF $\alpha$ restores glucocorticoid sensitivity in a mouse model of neutrophilic airway inflammation. Mucosal Immunol 2015;8:1212-25.

15. Wu LQ, Wang RL, Dai YR, et al. Roxithromycin suppresses airway remodeling and modulates the expression of caveolin-1 and phospho-p42/p44MAPK in asthmatic rats. Int Immunopharmacol 2015;24:247-55.

16. Dai Y, Li F, Wu L, et al. Roxithromycin treatment inhibits TGF- $\beta 1$-induced activation of ERK and AKT and downregulation of caveolin-1 in rat airway smooth muscle cells. Respir Res 2014;15:96.

17. Hough KP, Curtiss ML, Blain TJ, et al. Airway remodeling in asthma. Front Med (Lausanne) 2020;7:191.

18. Zhang J, Dong L. Status and prospects: personalized treatment and biomarker for airway remodeling in asthma. J Thorac Dis 2020;12:6090-101.

19. Danesi R, Lupetti A, Barbara C, et al. Comparative distribution of azithromycin in lung tissue of patients given oral daily doses of 500 and $1000 \mathrm{mg}$. J Antimicrob Chemother 2003;51:939-45.

20. Gibson PG, Yang IA, Upham JW, et al. Effect of azithromycin on asthma exacerbations and quality of life in adults with persistent uncontrolled asthma (AMAZES): a 
randomised, double-blind, placebo-controlled trial. Lancet 2017;390:659-68.

21. Zarogoulidis P, Papanas N, Kioumis I, et al. Macrolides: from in vitro anti-inflammatory and immunomodulatory properties to clinical practice in respiratory diseases. Eur J Clin Pharmacol 2012;68:479-503.

22. Blau H, Klein K, Shalit I, et al. Moxifloxacin but not ciprofloxacin or azithromycin selectively inhibits IL-8, IL6, ERK1/2, JNK, and NF-kappaB activation in a cystic fibrosis epithelial cell line. Am J Physiol Lung Cell Mol Physiol 2007;292:L343-52.

23. Cheng EH, Wei MC, Weiler S, et al. BCL-2, BCL-X(L) sequester $\mathrm{BH} 3$ domain-only molecules preventing $\mathrm{BAX}$ and BAK-mediated mitochondrial apoptosis. Mol Cell 2001;8:705-11.

24. Czabotar PE, Lessene G, Strasser A, et al. Control of

Cite this article as: Wu L, Yin J, Zhang Q, Wang M, Dai W, Zhou J, Dai Y. Azithromycin induces apoptosis in airway smooth muscle cells through mitochondrial pathway in a rat asthma model. Ann Transl Med 2021;9(14):1181. doi: 10.21037/ atm-21-3478 apoptosis by the BCL-2 protein family: implications for physiology and therapy. Nat Rev Mol Cell Biol 2014;15:49-63.

25. Moriya S, Che XF, Komatsu S, et al. Macrolide antibiotics block autophagy flux and sensitize to bortezomib via endoplasmic reticulum stress-mediated CHOP induction in myeloma cells. Int J Oncol 2013;42:1541-50.

26. Wan X, Zhao J, Xie J. Effects of mitochondrial ATPsensitive $\mathrm{K}(+)$ channel on protein kinase $\mathrm{C}$ pathway and airway smooth muscle cell proliferation in asthma. J Huazhong Univ Sci Technolog Med Sci 2012;32:480-4.

27. Peruzzo R, Szabo I. Contribution of mitochondrial ion channels to chemo-resistance in cancer cells. Cancers (Basel) 2019;11:761.

(English Language Editor: J. Jones) 